\title{
PIEDRA AZTECA DE SACRIFICIO CON CUAUHXICALLI (?)
}

\section{Elizabeth Baquedano}

En Septiembre de 1985, vi en el Instituto Guerrerense de la Cultura de Acapulco, una escultura monolítica, rectangular, con un recipiente integrado en la misma pieza; esto le confiere un carácter único dentro del repertorio escultórico mexica hasta donde nos es posible saber.

La escultura se encuentra decorada con bajorrelieves tanto en su parte superior como en sus lados. La decoración en la parte superior, consiste en tres franjas o registros esculpidos en relieve. El primer registro, de adentro hacia afuera está formado por signos calendáricos; el segundo, está formado por círculos concéntricos que en este caso parecen representar chalchiuitls, y el tercero, está formado por grecas escalonadas, propias del estilo de Mitla y de otros sitios precolombinos. Los lados de la piedra también se encuentran organizados en tres franjas principales, y, de arriba hacia abajo se ven dispuestas de la siguiente forma:

El primero y segundo registros están ocupados por círculos que nuevamente hacen alusión al carácter "precioso" de los chalchiuitls, y que probablemente representan sangre; el último, muestra rayos solares alternados con colgajos de chalchiuitls. Además, es importante señalar que la escultura aun posee restos de pintura roja con una base de estuco.

La materia prima es de origen volcánico, quizá basalto, y las medidas son: $77.5 \mathrm{cms}$. $\times 132.5 \mathrm{cms}$; la altura es de $25.5 \mathrm{cms}$. con patas, y sin estas, la altura es de $19.5 \mathrm{cms}$. Su estado de conservación en general es bueno, con excepción hecha de uno de sus extremos que se encuentra fracturado, así como uno de sus bordes superiores e inferiores. Ostenta cuarenta y dos cuadretes calendáricos, de los cuales cuatro se encuentran muy erosionados, por lo que su identificación resulta difícil.

Esta piedra a la que hemos denominado de sacrificio, es especialmente interesante porque combina tanto la plataforma para la ejecución del sacrificio, como el recipiente (cuauhxicalli) para la colocación de la sangre y el corazón de las víctimas. Sabemos de la existencia de una gran variedad de cuauhxicallis, así como de algunas piedras de sacrificio, pero es ciertamente raro encontrar las dos piezas en una. Por las descripciones de los cronistas del siglo XVI, tenemos noticia que existían "sacrificadores" que recibían el nombre de Cuauhxicalco, y, que de acuerdo a Durán, "era un patio muy encalado y liso, de espacio de siete brazas en cuadro. 
En este patio había dos piedras; a la una llamaban temalacatl, que quiere decir 'rueda de piedra', y a la otra llamaban cuauhxicalli, que quiere decir 'batea', Estas dos piedras redondas eran de a braza. Las cuales estaban fijadas en aquel patio, la una junto a la otra". ${ }^{1}$

Igualmente por los cronistas sabemos que el término cuauhxicalli se aplicaba no solamente al recipiente que contenía los corazones y la sangre de las víctimas que morían sacrificadas, sino también, a la piedra en donde se llevaba a cabo el sacrificio. Estas piedras en algunas ocasiones eran descritas como "mesas o altares de sacrificio"; en nuestro caso, definitivamente la escultura parece una mesa.

Como se dijo anteriormente, la piedra está esculpida en bajorrelieve con las representacions de los cuatro signos calendáricos:

Caña, Pedernal, Casa y Conejo, los signos del xiuhmolpilli de 52 años.

A continuación enunciamos el total de representaciones de los signos arriba citados y los coeficientes con que se ven acompañados en los cuadretes:

Caña $=1,3,4,5,6,8$ ó 9,11, 13. Se encuentran dos cuadretes más con el signo Caña, pero sus coeficientes están muy erosionados, por to que su lectura fue difícil de obtener.

Pedernal $=1,2,3,5,7,7$ u $8,8,9,13$.

Casa $=1,2,3,4,6,7$ u $8,8,10,11,14(?)$

Conejo $=1,3$ ó 4 ó $5,4,5,7,8,11,12,13$ y 4 nuevamente.

Existe un total de cuarenta y dos signos acompañados de coeficientes, de los cuales sólo treinta y ocho tienen numerales, los otros cuatro están deteriorados por lo que parecen no estar acompañados de numerales. Igualmente dudosa es su identificación, sin embargo, creemos que se trata de los signos Pedernal y Caña, ambos representados dos veces.

Aparece un cuadrete que fue especialmente difícil de identificar; a simple vista parece representar el signo $6=\hat{A}$ guila. Como en los casos anteriores, no estamos seguros que esta identificación sea correcta, ya que se encuentra en una zona muy deteriorada.

Tanto los signos Casa como Conejo aparecen representados diez veces respectivamente.

I Diego Durán, Historia de las Indias de Nueva España e Islas de Tierra Firme, edición prepatada por Ángel Ma. Garibay K., 2 v., México. Editorial Porrúa, 1984, t I, p. 98. 
El signo Pedernal está representado nueve veces, aunque existen dos cuadretes más que parecen ser representaciones del signo en cuestión; si estamos en lo correcto, el signo Pedernal aparecería representado once veces.

El signo Caña ocurre ocho veces, pero al igual que en el caso anterior, creemos que otros dos cuadretes más representan el signo Caña, por lo que éste estaría representado diez veces.

De los cuatro cuadretes arriba señalados no estamos totalmente seguros que su identificación haya sido correcta.

Si el ciclo empezara con el signo 1-Conejo y procediera a través de los cuatro signos trece veces, entonces nuestra escultura en cuestión sería la representación de un "siglo" Azteca de 52 años o xiuhmolpilli.

Queremos hacer hincapié que la lectura de los signos y de los numerales en más de una ocasión resulta muy complicada, especialmente la que se refiere al día 6-Águila. No estamos seguros que esta identificación sea muy fidedigna, pues no se trata de ninguno de los portadores de los años Conejo, Caña, Pedernal o Casa, pero visualmente asi parece,

Existe otro problema en el numeral 14-Casa, ya que tampoco va de acuerdo con las trecenas del xiuhmolpilli. Estos puntos presentan dificultades, así como el hecho que no tengamos datos acerca de la proveniencia de la escultura. ¿Podría pues tratarse de una falsificación?

A favor podemos decir que el estilo con el que la obra está trabajada, es muy semejante al estilo de los códices de la Mixteca-Puebla que se "transcribían" en piedra. De este tipo de esculturas tenemos muchos ejemplos. El material con el que la pieza está trabajada es el comunmente utilizado y los restos de pintura son bastante parecidos a los que aparecen en otras esculturas Mexicas; tal es el caso de la Piedra de Tizoc que conserva restos de color rojo. Por el momento no es posible decir más sobre la autenticidad de la pieza; no todas las obras que se conservan del México Antiguo tienen una explicación inmediata, igualmente, no siempre sabemos acerca de su uso y menos aun de su significado. Estamos conscientes que no hemos realizado un estudio calendárico de la escultura, esa no es la intención. Queremos presentar una obra enigmática tanto por su contenido como por su forma, y abrir el debate inos encontramos ante una obra auténtica Mexica o se trata de una falsificación? Trátese de una u otra posibilidad, no deja de ser una pieza interesante que vale la pena incluir en el corpus escultórico Mexica. Cabe mencionar que en el Estado de Guerrero, Fredrick Peterson ${ }^{2}$ ha detectado varios talleres de fabrica-

${ }^{2}$ Fredrick A Peterson, Falsificaciones Arqueológicas en el Estado de Guerreto, México, Tlatoani, vol. I (3-4), mayo-agosto 1952. pp. 15-19 
ción de objetos prehispánicos en Taxco, Iguala y Teleloapan, así como por lo menos cinco familias en Guerrero que se especializan en la falsificación de objetos arqueológicos.

Quizá más investigaciones nos revelen si la escultura descrita es o no una piedra de sacrificio original o si se trata de una falsificación producto de la habilidad y destreza de algún artesano.

\section{BIBLIOGRAFİA}

Beyer, Hermann, "La Piedra del Sacrificio Gladiatorio" del Museo Nacional de Arqueología, México, Revista de Revistas, 1920.

Beyer, Hermann y Nicholson, Henry B., Dos Estudios sobre Piedras Aztecas del Sacrificio Gladiatorio. México, El México Antiguo, 1955, vol. VIII, pp. 85-134.

DurÁn, Diego, Historia de las Indias de Nueva España e Islas de Tierra Firme, edición preparada por Ángel Ma. Garibay K., 2 v., México, Editorial Porrúa, 1984.

Peterson, Fredrick A., Falsificaciones Arqueológicas en el Estado de Guerrero, México, Tlatoani, vol. I (3-4), mayo-agosto 1982. pp. 15-19.

UMBERGER, EMILY, A Reconsideration of Some Hieroglyphs on the Aztec Calendar Stone, en prensa.

Nota: La autora desea agradecer a los doctores: Beatriz de la Fuente por estimularla a publicar sus observaciones sobre esta escultura, a Warwick Bray por leer y discutir la versión preliminar de este artículo, y a Emily Umberger, quien vio las fotografías de la pieza y a primera vista opina que se trata de una falsificación. 


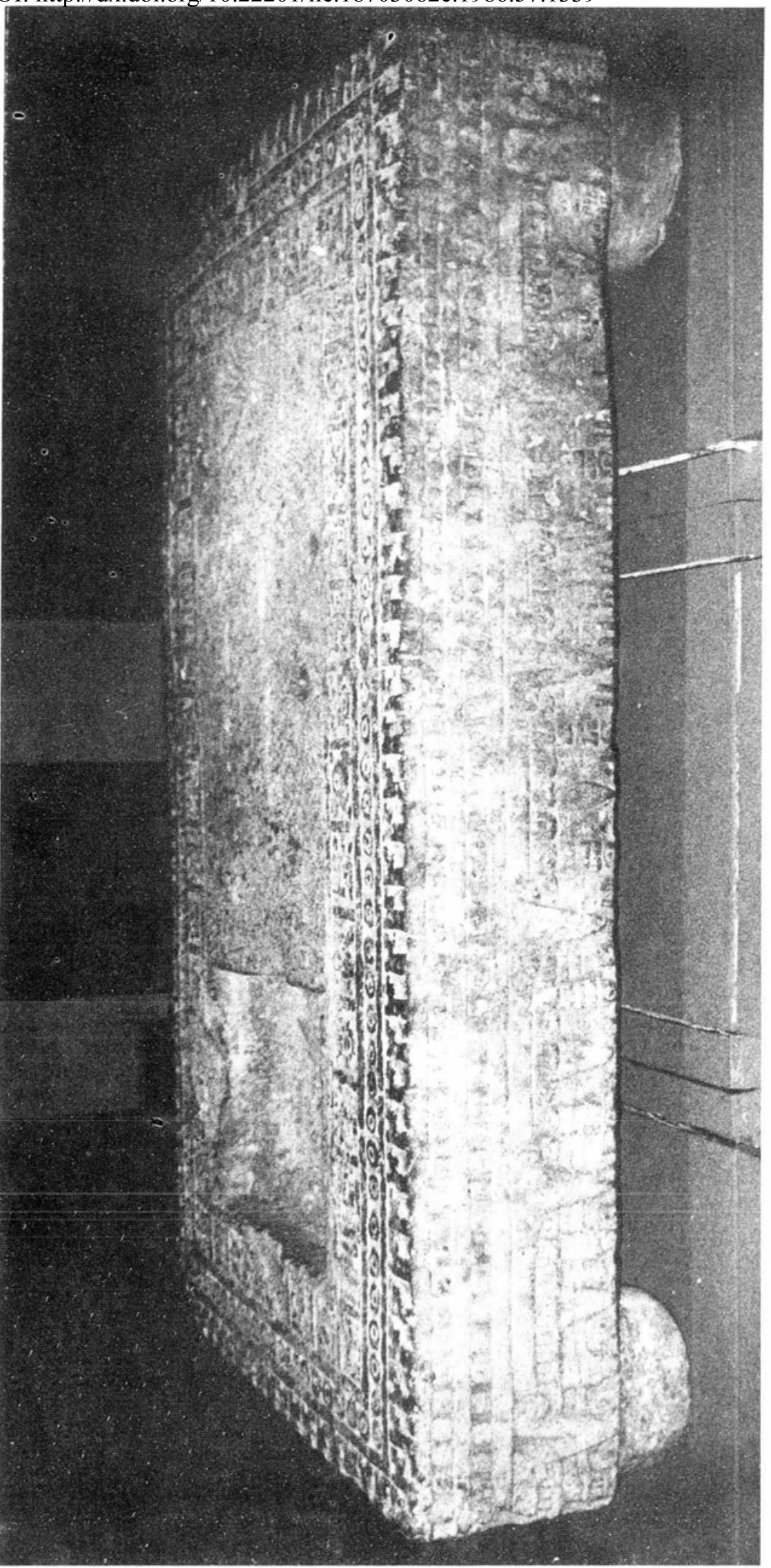

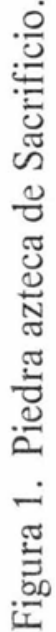


DOI: http://dx.doi.org/10.22201/iie.18703062e.1986.57.1339

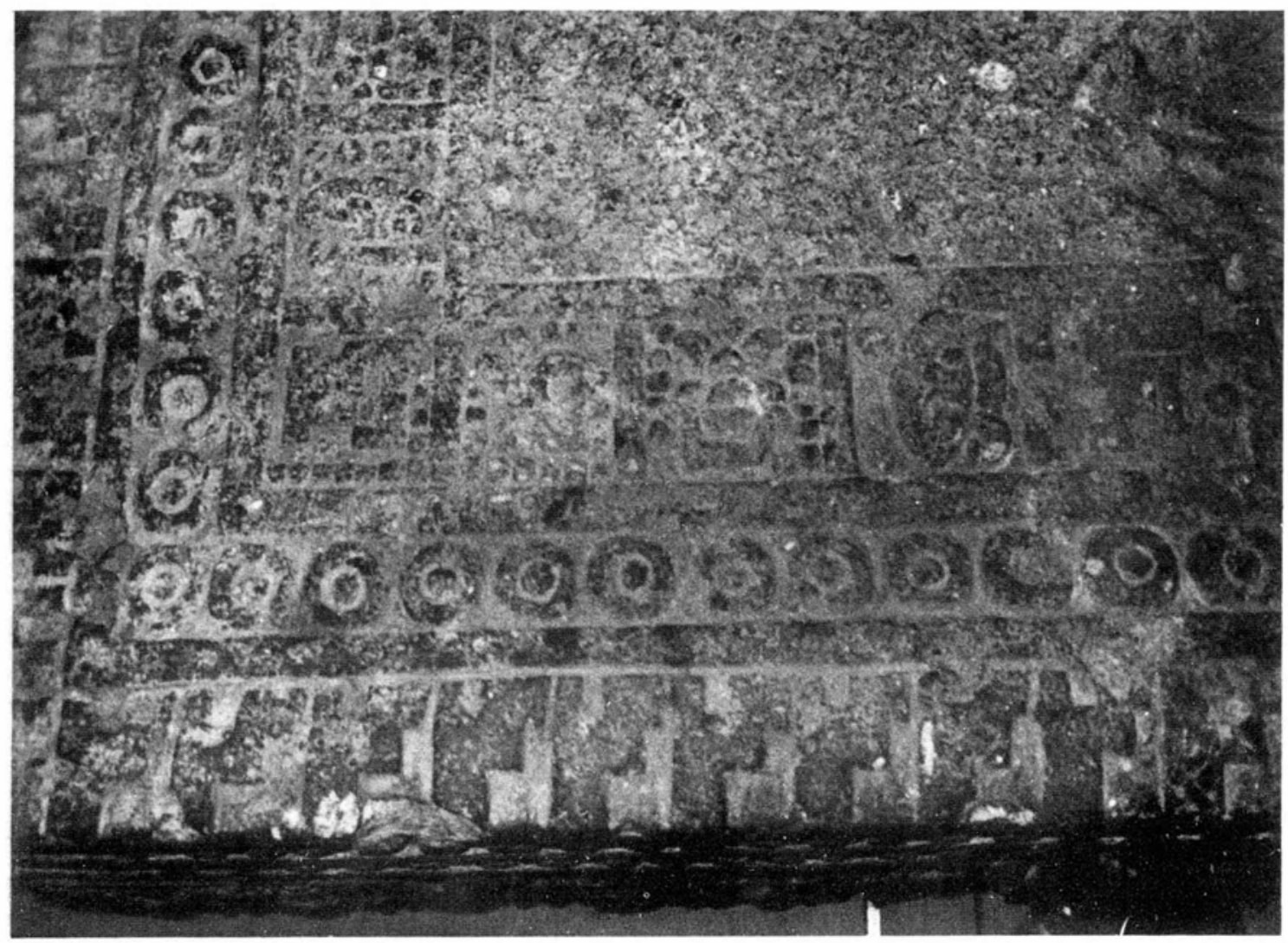

Figura 2. Detalle. 


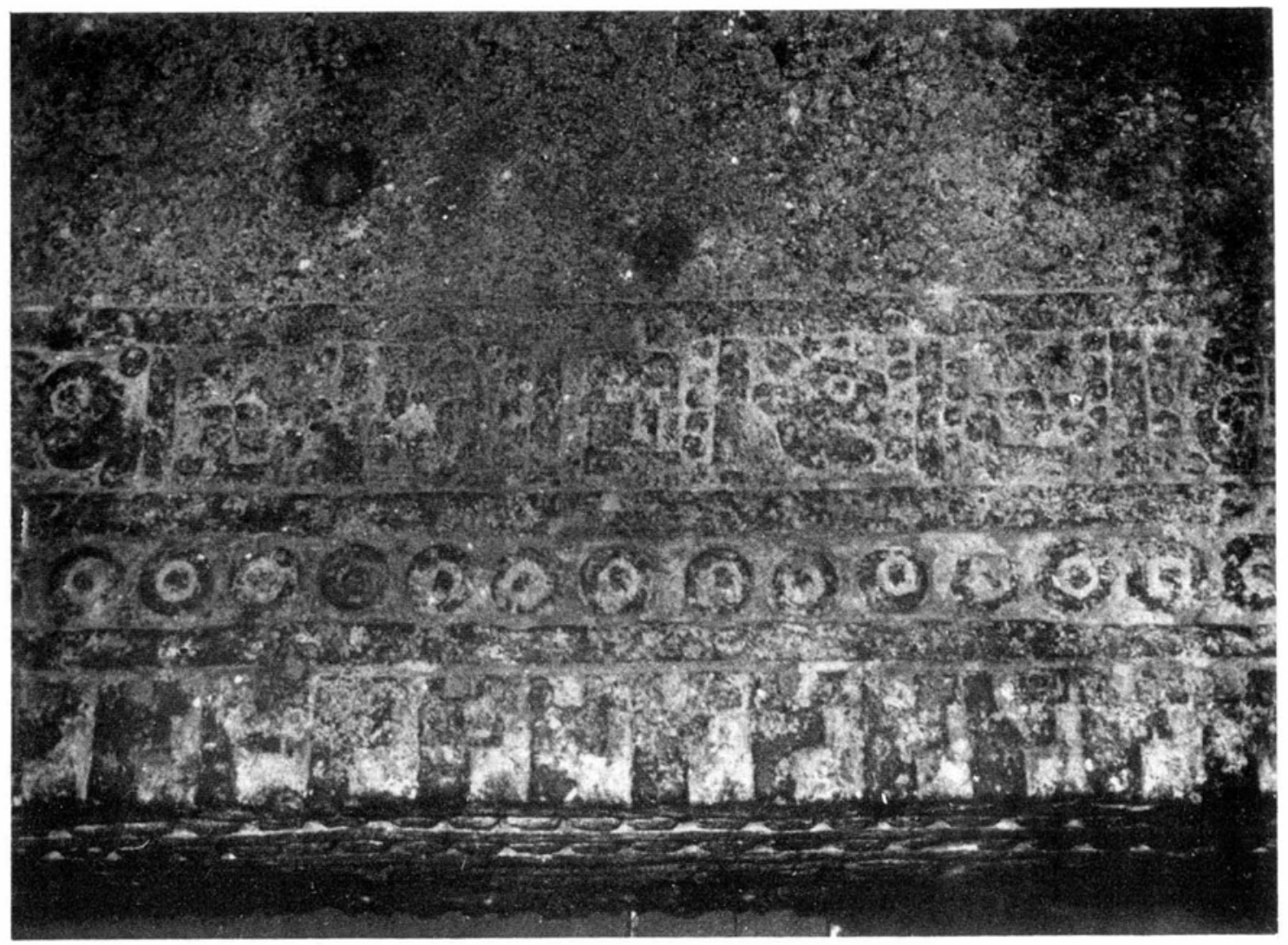

Figura 3. Detalle. 
DOI: http://dx.doi.org/10.22201/iie.18703062e.1986.57.1339

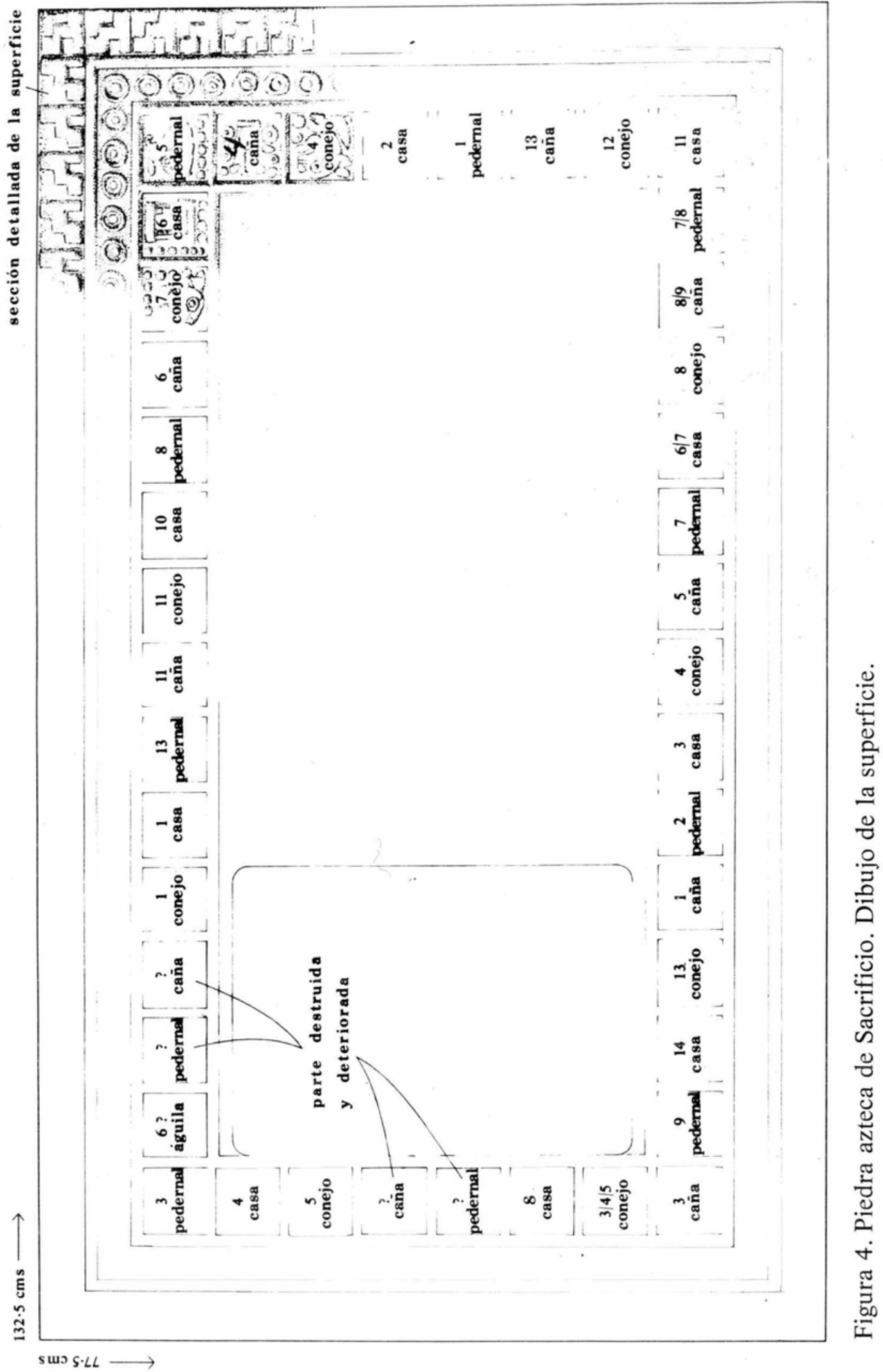

